\title{
Orthodontic treatment needs in Saudi young adults and manpower requirements
}

Fadia M. Al-Hummayani, BDS, MSc, Salwa M. Taibah, MSc, PhD.

\begin{abstract}
الأهداف : تقييم احتياجات علاج تقويم الأسنان باستخدام مؤشر

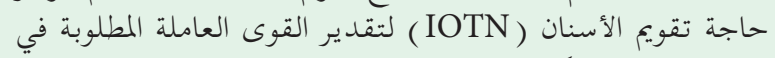
مدينة جدة، المملكة العربية السعودية .

الطريقة : أجريت دراسة مقطعية من شهر نوفمر 2017 إِلى إِبريل

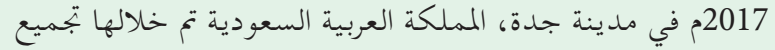

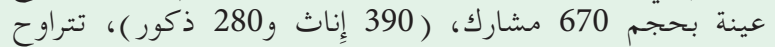

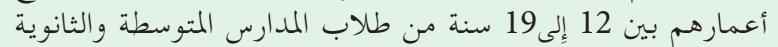

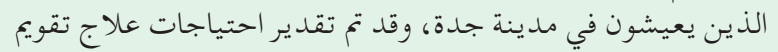

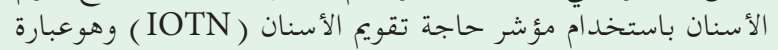

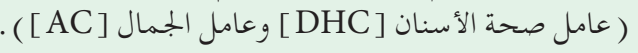

النتائج: أوجدت النتائج أن 24.3\%) من الحالات التي لديها

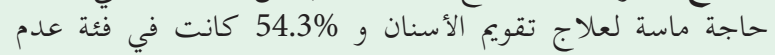

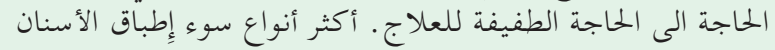

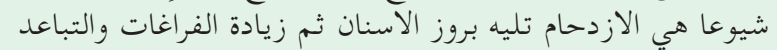

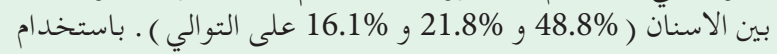

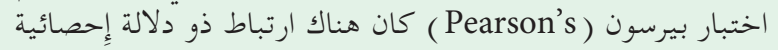

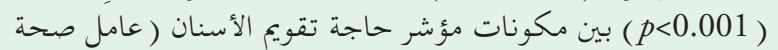

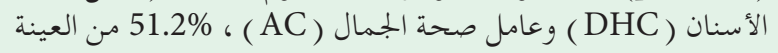

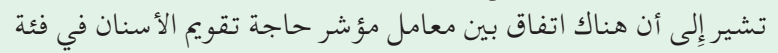

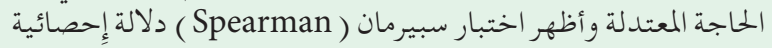

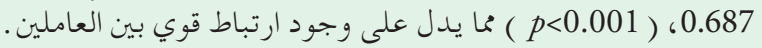

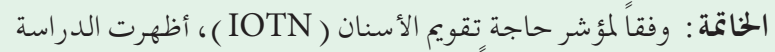

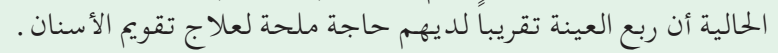

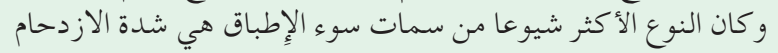

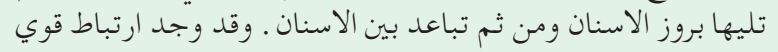

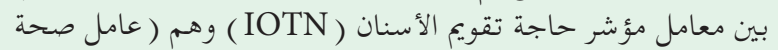

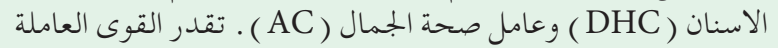

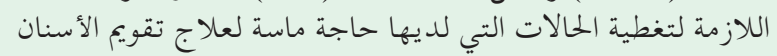
من 90 إلىى 110 أخصائي تقويم أسنان . لحاتجة
\end{abstract}

Objectives: To evaluate orthodontic treatment needs using the index of orthodontic treatment need (IOTN) components and to estimate the required manpower in the city of Jeddah, Saudi Arabia.
Methods: A cross-sectional study involving 670 participants (390 females and 280 males) collected between November 2016 and April 2017, whose ages ranged from 12-19 years from secondary and high school students. Treatment needs were estimated using the IOTN components, dental health component (DHC), and aesthetic component (AC).

Results: The results according to the severity of malocclusion using IOTN-DHC found that $24.3 \%$ of the cases required severe/extreme need and 54.3\% were in the no/slight need category. The most frequent types of malocclusion were crowding (48.8\%) followed by increased overjet (21.8\%), and spacing (16.1\%). Using Pearson's Chi-squared test, there was a statistically significant association $(p<0.001)$ between IOTN-DHC and IOTN-AC; $51.2 \%$ of the sample was in agreement at the mild need category, indicating a strong correlation, with a coefficient of 0.687 .

Conclusion: According to the IOTN's components, the present study showed that almost one-quarter of the sample had a severe/extreme need for orthodontic treatment. The most frequent type of malocclusion traits according to the severity was crowding followed by increased overjet and then spacing. The Ministry of Health must employ 90-110 orthodontists in Jeddah to meet the demands of the definite needs for orthodontics in adolescents.

Saudi Med J 2018; Vol. 39 (8): 822-828 doi: 10.15537/smj.2018.8.22337

From the Department of Orthodontic, Faculty of Dentistry, King Abdulaziz University, Jeddah, Kingdom of Saudi Arabia.

Received 19th February 2018. Accepted 27th June 2018.

Address correspondence and reprint request to: Dr. Fadia $M$. Al-Hummayani, Department of Orthodontic, Faculty of Dentistry, King Abdulaziz University, Jeddah, Kingdom of Saudi Arabia. E-mail:falhummayani@kau.edu.sa

ORCID ID: orcid.org/0000-0003-4587-3043 
Tn planning of orthodontic services, it is essential 1 to determine and measure the treatment needs in a population. ${ }^{1}$ The main reason for orthodontic treatment is enhancement of appearance from the patient's point of view. ${ }^{1,2}$ However, the need for orthodontic treatment is not influenced only by the patient's perceptions; the orthodontist's clinical examination is essential to support this perception and add greater awareness of the malocclusion situation. ${ }^{2,3}$ Several indices were designed to classify malocclusion into groups in relation to the degree of treatment needed. Occlusal indices are used to recognize and rank the treatment needed in epidemiological studies and to improve the reliability of treatment facility. ${ }^{1,2}$ The index of orthodontic treatment needs (IOTN) is one of the most commonly used indices to measure orthodontic treatment needs. ${ }^{3,4}$ It has 2 distinct components, the dental health component (DHC) and the aesthetic component (AC). The DHC is the clinical component of the IOTN and is composed of 5 grades varying from grade one, "no need for treatment," to grade 5, "extreme need". 5 The AC is the subjective component of the IOTN and is composed of a scale of 10 photographs that measure the ranges of anterior teeth attractiveness. ${ }^{5}$ When comparing the IOTN to other treatment need indices, the IOTN has been found to be reproducible, valid, and accurate, with high specificity and sensitivity . 2,6-8

Within the last 10 years, few epidemiological studies have been conducted in the western region of Saudi Arabia on the malocclusion status of young adults and their orthodontic treatment needs using the IOTN. ${ }^{6,7,9}$ Several studies that estimate the orthodontic manpower need were found; however, all of them were carried out in countries other than Saudi Arabia. ${ }^{10,11}$ No published research was found to estimate the orthodontic manpower requirements in the Kingdom; therefore, the importance of this study arises from the fact that Saudi Arabia provides free public orthodontic services. Thus, a careful estimation of the funds and manpower are essential in order to provide decisions to deliver such services. Therefore, the evaluation of orthodontic treatment needs will scientifically support the proper direction of government resources.

The aim of the present study is to evaluate the orthodontic treatment needs using the IOTN components and to estimate the required manpower in Jeddah, Saudi Arabia. Furthermore, to assess the

Disclosure. Authors have no conflict of interests, and the work was not supported or funded by any drug company. most frequent types of malocclusion traits according to severity, to investigate gender distribution and gender differences of malocclusion traits. Lastly, to find the degree of correlation between the IOTN-DHC and the IOTN-AC in order to assess their agreement.

Methods. Research Ethics Committee at King Abdulaziz University in Jeddah, Saudi Arabia, approved this cross-sectional descriptive study (RCE \#085-16). This study was designed according to the principles of Helsinki declaration.

The sample of the present study was collected from public and private secondary and high schools in Jeddah, Saudi Arabia between November 2016 and April 2017. The sample size was estimated using a 95\% confidence level and 5\% margin of error with the RAOSOFT online sample size calculator (http://www.raosoft.com/ samplesize.html). The recommended sample size of Saudi teenage males and females population living in the Western region of Saudi Arabia was 385 subjects.

We invited 975 adolescents to participate in the present study; however, 305 adolescents were excluded from the study because they do not fit the study criteria.

Inclusion criteria were: students with consent form obtained from them and their guardians, age between 12-19 years. Exclusion criteria were: students who have carried out orthodontic treatment or in the middle of the treatment and students with craniofacial anomaly.

The final sample size was a total of 670 students, aged 12-19 years, who were selected from different demographic areas of Jeddah. Demographic data collected from all participants included date of birth, age, gender, level of education, and type of schooling.

Malocclusion assessment. The IOTN was established by Brook and Shaw in 1989, it incorporates 2 components; the DHC and AC. This index was designed to assess the orthodontic treatment need and the severity of malocclusion. ${ }^{1}$ The students' malocclusions were examined under natural light using the DHC and AC of the IOTN.

Malocclusion severity was ranked following the DHC component of IOTN to: 1-2 imply no/little treatment need, 3 imply moderate/borderline treatment need, and 4-5 imply severe/extreme treatment need. ${ }^{5}$ The malocclusion traits were overjet, anterior crossbite, posterior crossbite, anterior open bite, anterior overbite, crowding, and spacing. The highest numerical values of the malocclusion severity were recorded. The IOTN-AC was used to measure the person's self-perception of his/her aesthetic. It is composed of 10 photographs representing different severity and attractiveness levels of anterior malocclusion. It has 10 grades; grades 
1-4 represent no/slight need, grades 5-7 represent borderline/moderate need, and grades 8-10 represent severe/extreme need for orthodontic treatment. ${ }^{5}$ The examiner selected the photograph that most represented the participants' anterior dental appearance.

For the examiners' calibration, 30 cases were examined and re-examined by both researchers within a one-week interval.

Statistical analyses. Statistical analyses were performed using the Statistical Package for the Social Sciences SPSS version 20 (IBM Corp., Armonk, NY, USA). Descriptive analyses of the data were performed. Pearson's chi-square test was performed to find any gender differences in the IOTN-DHC and IOTN-AC levels of severity and malocclusion traits. Pearson's Chi-square test was used to find the correlation between the IOTN-DHC and the IOTN-AC. Spearman's correlation was used to find the correlation coefficients between the IOTN-DHC and the IOTN-AC.

Results. The sample was composed of 670 participants, 390 females (58.2\%), and 280 males (41.8\%), with a mean age of 15.32 and SD of 1.81 years. The secondary students comprised 307 (45.8\%) and high school students 363 (54.2\%). The public students comprised 300 (44.8\%) and private school 370 (55.2\%). The intra-examiner kappa values for the DHC was 0.91 and $\mathrm{AC}$ was 0.85 , indicating good intra-examiner reproducibility.

According to the IOTN-DHC, $24.3 \%$ of the cases required severe/extreme need for orthodontic treatment. The highest number of cases fell into the no/slight need category (51.3\%). The moderate/ borderline need category was third. Table 1 \& Figure 1 represent this distribution. No statistically significant difference between genders according to the severity of malocclusion $(p=0.89)$ for no/slight need, $(p=0.418)$ for moderate/borderline need and $(p=0.35)$ for severe/ extreme need.

Table 2 shows the gender distribution of the IOTN-AC grades. It reveals that the highest number of cases fell in the no/slight need of treatment $(65.8 \%)$, followed by moderate/borderline need $(26.6 \%)$, and severe/extreme need of treatment was last (7.6\%). No statistically significant differences between genders according to the IOTN-AC $(p=0.151)$ for no/slight need, $(p=0.19)$ for moderate/borderline need, and $(p=0.689)$ for severe/extreme need.

Figure 2 shows the distribution of different types of malocclusions in the total sample and in the males and females. Crowding was the most frequent type of malocclusion, which represented approximately $49 \%$ of the total sample. The second and the third most common types of malocclusion were increased overjet $(22 \%)$ and spacing (16\%). The least frequent type of malocclusion was the anterior open bite, which represented $2 \%$ of the total sample.

Table 3 shows that there was a highly statistically significant difference between males and females in the frequency of crowding at $p<0.001$ and overjet at $p=0.037$. Spearman's test showed a statistically significant $(p<0.001)$ strong correlation with a coefficient of 0.687 (Table 4).

Using Pearson's Chi-squared test, there was a statistically significant correlation $(p<0.001)$ between the IOTN-DHC and IOTN-AC; $51.2 \%$ of the sample was in agreement in the mild need category, while the agreements in the moderate need levels were $10.7 \%$ and severe were $6.7 \%$.

Manpower estimation. The birth cohort in the city of Jeddah is estimated to be approximately $35,000 .^{12}$ The present study showed that the severe/extreme need of orthodontic cases represent approximately 25\%, suggesting that approximately 9,000 of each birth cohort will have severe/extreme orthodontic treatment needs. Assuming a full-time orthodontist can accept an average of 80-100 new cases per year; therefore, the Saudi Ministry of Health must employ 90-110 orthodontists in Jeddah to meet the demand of the needs for orthodontics in adolescents. This number must be increased to $160-200$ orthodontists if the Ministry of Health aims to include moderate orthodontic treatment needs cases in its service plan.

Discussion. The revolution in communication and social media has led to changes in the beauty perception among most social media users, especially young adults. ${ }^{13,14}$ The results could be the lack of acceptance of mild malocclusions and seeking a Hollywood smile. Added to this is the increased knowledge and awareness of what changes in orthodontic treatment can accomplish. These factors have increased the demand for orthodontic treatment in the Saudi population. ${ }^{2}$

In a country such as Saudi Arabia where orthodontic treatment is free, it is important to carefully screen the cases that could benefit from this service. A better understanding of how orthodontists evaluate the severity of malocclusions will assist in the estimation of the required manpower. This estimation will also help shed some light on the future vision of the Ministry of Health to provide suitable clinical services for the public and to hire the required number of orthodontists. It will also assist the universities and the Saudi Mission for Health Specialties to estimate the required numbers of dentists that should be accepted in postgraduate 
Table 1 - Index of orthodontic treatment need - dental health component (IOTN-DHC) distribution according to gender.

\begin{tabular}{|c|c|c|c|c|}
\hline IOTN-DHC & $\begin{array}{c}\text { Total sample } \\
\text { n (\%) }\end{array}$ & $\begin{array}{l}\text { Male } \\
\text { n (\%) }\end{array}$ & $\begin{array}{l}\text { Female } \\
\text { n (\%) }\end{array}$ & $\begin{array}{c}\text { Pearson's } \\
\text { Chi-squared } \\
\text { test ( } p \text {-value) }\end{array}$ \\
\hline No/slight need & $364 \quad(54.3)$ & $153(54.6)$ & $211 \quad(54.1)$ & 0.89 \\
\hline Moderate/borderline need & $143 \quad(21.3)$ & $64 \quad(22.9)$ & $79 \quad(20.3)$ & 0.418 \\
\hline Severe/extreme need & $163(24.3)$ & $63 \quad(22.5)$ & $100 \quad(25.6)$ & 0.35 \\
\hline Total & 670 & 280 & 390 & \\
\hline
\end{tabular}

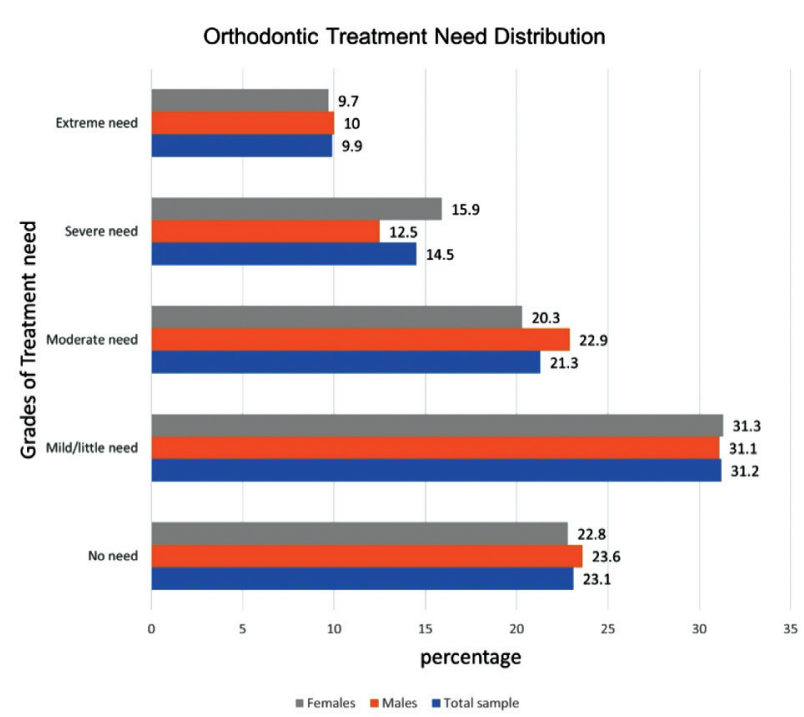

Figure 1 - Index of orthodontic treatment need - dental health component (IOTN-DHC) distribution according to gender.

programs.

The IOTN is the most commonly used index, especially among epidemiological studies performed in the Middle East region. ${ }^{2}$ According to the IOTN-DHC, this study showed that $24.3 \%$ of the cases had severe/ extreme need for orthodontic treatment. Variable percentages have been reported by other studies performed in Arab countries. For example, Omer et al reported $31 \%$ of severe/extreme need cases in Lebanon, ${ }^{15}$ while Al-Zubair showed a $19 \%$ of severe/ extreme malocclusion among 12 years old Yamani school students, ${ }^{16}$ Hammad and Awad found that almost $20 \%$ of their sample of Egyptian school children was in the severe/extreme need category. ${ }^{17}$ Alatrach et al studied a Syrian sample and found that $38 \%$ of their sample fell into the severe need category. ${ }^{1}$ Far Eastern countries reported a similar percentage to the present study. Cai et $\mathrm{al}^{18}$ found that $24.1 \%$ of their Chinese sample had severe/extreme needs for orthodontic treatment, and Zamzuri et al, ${ }^{19}$ showed a $27 \%$ of severe/ extreme need among their Malaysian sample. On the other hand, a higher percentage of severe/extreme need cases were found in other Middle Eastern countries such as Turkey and Iran, where researchers found a percentage of $45.9 \%$ and $62.7 \% .^{20,22}$ In addition, $47.1 \%$ of referred Pakistani patients had a severe/extreme need for orthodontic treatment. ${ }^{23}$ In contrast to the present study, this difference might be due to variability in the perceptions of the referring dentists, who assessed the malocclusion with different rankings of esthetic factors vs measurable treatment needs. Ethnicity and cultural differences could also be contributing factors.

Studies carried out in different areas of Saudi Arabia also showed variable results. Gudipaneni et $\mathrm{al}^{24}$ showed that $21 \%$ of the adolescents of the northern region of Saudi Arabia have a severe/extreme orthodontic needs. However, other studies found a much higher percentage such as the study carried out in the central region of Saudi Arabia by Al-Jobair. He found that $70 \%$ of the patients sought orthodontic treatment at King Saud University were reported as having severe/extreme orthodontic treatment needs. Similarly, Hassan and Hassan et al, in 2006 and 2014 showed that $71.6 \%$ and $52.5 \%$ of patients seeking orthodontic treatment at King Abdulaziz University (KAU) in the western region of the Kingdom were in the severe/extreme need category. ${ }^{2,6,9}$ This considerable difference between the present research and the other studies could be attributed to the fact that the sample subjects in the present study were students who were not seeking orthodontic treatment. However, Al-Jobair, ${ }^{2}$ Hassan $^{6}$ and Hassan et al's studies ${ }^{9}$ were performed either on referred patients or on those seeking orthodontic treatment at the university's orthodontic clinics, which might explain the higher percentages.

We also noticed a descending pattern of the percentages in severe/extreme orthodontic treatment needs from all the studies performed in Jeddah in 2006 (71.6\%), ${ }^{6} 2014(52.5 \%),{ }^{9}$ and present study (24.3\%). 
Table 2 - Index of orthodontic treatment need - aesthetic component (IOTN-AC) distribution according to gender.

\begin{tabular}{lcccc}
\hline IOTN-AC & $\begin{array}{c}\text { Total sample } \\
\mathbf{n}(\%)\end{array}$ & $\begin{array}{c}\text { Male } \\
\mathbf{n}(\%)\end{array}$ & $\begin{array}{c}\text { Female } \\
\mathbf{n}(\%)\end{array}$ & $\begin{array}{c}\text { Pearson's } \\
\text { Chi-squared } \\
\text { test }(p \text {-value })\end{array}$ \\
\hline No/slight need & $441(65.8)$ & $193(68.9)$ & $248(63.6)$ & 0.151 \\
Moderate/borderline need & $178(26.6)$ & $67(23.9)$ & $111(28.5)$ & 0.190 \\
Severe/extreme need & $51(7.6)$ & $20(7.1)$ & $31(7.9)$ & 0.689 \\
Total & $\mathbf{6 7 0}$ & 280 & 390 & \\
\hline \multicolumn{5}{l}{ IOTN - index of orthodontic treatment need, AC - aesthetic component } \\
\hline
\end{tabular}

Table 3 - Malocclusion traits in males, females and the total sample showing Pearson's chi-squared test.

\begin{tabular}{lrrrrrrr}
\hline $\begin{array}{l}\text { Type of } \\
\text { malocclusion }\end{array}$ & $\begin{array}{c}\text { Total sample } \\
\mathbf{n}(\%)\end{array}$ & \multicolumn{2}{c}{$\begin{array}{l}\text { Male } \\
\text { n }(\%)\end{array}$} & $\begin{array}{l}\text { Female } \\
\text { n }(\%)\end{array}$ & $\begin{array}{c}\text { Pearson's } \\
\text { Chi-squared } \\
\text { test }(p \text {-value })\end{array}$ \\
\hline Overjet & 146 & $(21.8)$ & 50 & $(17.9)$ & 96 & $(24.6)$ & 0.037 \\
Anterior crossbite & 26 & $(3.9)$ & 8 & $(2.9)$ & 10 & $(4.6)$ & 0.245 \\
Posterior crossbite & 20 & $(3.0)$ & 5 & $(1.8)$ & 8 & $(3.8)$ & 0.122 \\
Anterior open bite & 32 & $(4.8)$ & 10 & $(3.6)$ & 12 & $(5.6)$ & 0.216 \\
Anterior overbite & 11 & $(1.6)$ & 2 & $(0.7)$ & 6 & $(2.3)$ & 0.109 \\
Crowding & 327 & $(48.8)$ & 161 & $(57.5)$ & 194 & $(42.6)$ & $<0.001$ \\
Spaces & 108 & $(16.1)$ & 44 & $(15.7)$ & 64 & $(16.4)$ & 0.809 \\
\hline
\end{tabular}

Table 4 - Spearman's correlation coefficient between the index of orthodontic treatment need components; dental health component (IOTN-DHC) and the aesthetic component (IOTN-AC).

\begin{tabular}{lrrrrrrrr}
\hline IOTN-AC & \multicolumn{4}{c}{$\begin{array}{c}\text { IOTN-DHC } \\
\text { n (\%) } \\
\text { Moderate }\end{array}$} & \multicolumn{1}{c}{ Severe } & $\begin{array}{c}\text { Spearman's } \\
\text { correlation } \\
\text { coefficient }\end{array}$ & $\begin{array}{c}\text { Sig. } \\
\text { (2-tailed) }\end{array}$ \\
\hline Mild & 343 & $(51.2)$ & 67 & $(10.0)$ & 31 & $(4.6)$ & & \\
Moderate & 17 & $(2.5)$ & 72 & $(10.7)$ & 87 & $(13.0)$ & $0.687^{* *}$ & $<0.001$ \\
Severe & 4 & $(0.6)$ & 4 & $(0.6)$ & 45 & $(6.7)$ & & \\
Total & 364 & $(54.3)$ & 143 & $(21.3)$ & 163 & $(24.3)$ & \\
\hline \multicolumn{6}{c}{ IOTN-AC - index of orthodontic treatment need; aesthetic component, } \\
IOTN-DHC - index of orthodontic treatment need components; dental health \\
\hline
\end{tabular}

This could be attributed to the changes in awareness of malocclusions' effects on oral health and an increase in the knowledge of what orthodontic treatment can offer to improve dental health and aesthetics. This has encouraged parents to seek early interceptive orthodontics. Thus, Phase 1 of treatment concepts will affect the severity of cases, leading to a decrease in grade 4 and 5 cases.

Severe/extreme need category patients should be the first priority for free orthodontic treatment. Hassan's 2006 study ${ }^{6}$ showed otherwise: patients attending KAU clinics and obtaining free orthodontic treatment had malocclusions of grades 1 and 2 categories of IOTN components, significantly higher than those attending private clinics, and cases with high needs at grades 4 and 5 were greater at private clinics in the western region. This could be the result of the demand for quick treatment of those patients to improve their dental health and attractiveness, and loading the KAU free clinics with cases that have less needs increasing the length of the waiting list. King Abdulaziz University screening clinics have recently started to use the IOTN-DHC as a tool for 


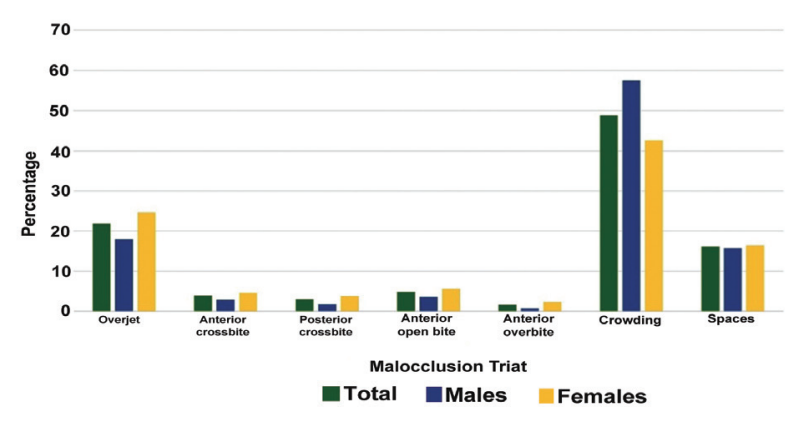

Figure 2 - Distribution of malocclusion triats according to gender.

screening patients and directing them to postgraduate or specialty clinics according to case severity. This arrangement will benefit those with moderate and severe needs from this free governmental service, but more investigation is necessary to evaluate this situation in the future.

Subjective need assessment (IOTN-AC) showed almost $8 \%$ of the cases were considered severe/extreme need. Although the severe/extreme orthodontic treatment need in the IOTN-AC was much lower than in the IOTN-DHC (24.3\%), it is essential to assess orthodontic cases using AC to avoid any effect of malocclusion on self-perception and social life.

There is a statistically significant correlation between the IOTN-DHC and the IOTN-AC, but it was mainly at the no/mild need level at $51.2 \%$, while it represented $6.7 \%$ of the cases at the severe/extreme need level. This could be attributed to the fact that the IOTN-DHC includes posterior malocclusions while the AC focuses only on the subjective effects of anterior malocclusions. It is important to highlight the strong statistically significant correlation between the IOTN-DHC and the IOTN-AC, which represents the high reliability and applicability of the IOTN-AC in the Saudi population.

The present study showed that the most frequent and severe malocclusion traits were crowding $(57.5 \%)$ followed by increased overjet and spacing (17.9\% and $15.7 \%$,). Several other studies evaluated the most frequent types of malocclusion traits. Hassan in 2006 conducted a cross-sectional study on Saudi adults seeking orthodontic treatment at public and private clinics in the western region of the Kigndom. He found that crowding was first followed by crossbite and increased overbite and overjet $(89.1 \%, 44.5 \%$, and $33.6 \%) .{ }^{6}$ Al-Jobair et al's review of 300 orthodontic study models found a very similar sequence of traits to the present research, except increased overbite and crossbite were third (36\%), with $96 \%$ of the sample showing crowding and $64.7 \%$ showing increased overjet. ${ }^{2}$ This difference in the percentages is due to the fact that the 2 studies mentioned above researched the incidence of these malocclusion traits while the present study focused on traits that contributed to the severity of the case.

Other studies conducted in the Middle East on the prevalence of malocclusion traits revealed conflicting results. Some showed a similar prevalence sequence of malocclusion traits according to severity as the present study. Hammand and Awad's study ${ }^{17}$ of Egyptian participants found that severe crowding was the most common malocclusion trait in $27.5 \%$ of their sample followed by increased overjet at $20.4 \%$. A study on the Iranian population showed the same results, with crowding being the most common malocclusion trait in their sample at $62.7 \%$ and increased overjet at $22.7 \%{ }^{25}$ However, other studies showed slightly different prevalence patterns as seen in Bugaighis and Karanth's study ${ }^{26}$ of 343 Libyan school children. It was found that $55.1 \%$ showed increased overbite, followed by $48.4 \%$ with increased overjet, whereas crowding had the lowest percentage at $10 \%$.Moreover, Seddiqui et al concluded that overjet represented the most common malocclusion traits of their total sample at $41.3 \%$, followed by crowding at $26.4 \% .^{23}$

A strong correlation was found between the IOTN-DHC and the IOTN-AC as represented by Spearman's correlation coefficient. It showed a strong $(p<0.001)$ statistically significant correlation with a coefficient of 0.687 supporting that the IOTN components are accurate, reproducible, and valid for use in epidemiological studies in Saudi Arabia. This was also proven by other studies that found that the IOTN components have high specificity and sensitivity. ${ }^{2,6-8}$

The main limitation of the present study, is that it concentrated on the adolescent age group excluding the early mixed dentition, and adult cases that have a severe/extreme or moderate orthodontic need, which might increase the required manpower in the city of Jeddah. Future researches about these age groups will add to the understanding of the orthodontic treatment needs and the expected manpower.

Clinical implication. The suggested estimation of manpower will help shed some light on the future vision of the Ministry of Health in providing suitable clinical services for the public and hiring the required number of orthodontists. It will also help the universities and the Saudi Mission for Health Specialties to estimate the required numbers of dentists that should be accepted to postgraduate orthodontic programs. 
In conclusion, one-quarter of the orthodontic cases in the city of Jeddah fall in the severe/extreme orthodontic treatment need. Manpower estimation of 90-110 orthodontists to cover the severe/extreme need cases, and 160-200 orthodontists if moderate need cases are to be included. The most frequent type of malocclusion traits according to the severity was crowding followed by increased overjet then spacing; the least frequent type of malocclusion was anterior open bite. Statistically significant differences between the genders were found, with males showing more crowding and females showing more increased overjet. Statistically significant correlation $(p<0.001)$ between the IOTN-DHC and IOTN-AC indicating that they are reliable and applicable indexes.

Acknowledgment. The authors would like to thank Professor Hebbal Mamata Department of Preventive Dentistry, Faculty of Dentistry, Princess Nourah bint Abdulrahman University, Riyadh, Saudi Arabia for her valuable contribution. The authors also would like to thank the Elsevier Editing Service Company for English language editing.

\section{References}

1. Alatrach A, Saleh F, Osman E. The prevalence of malocclusion and orthodontic treatment need in a sample of Syrian children. European Scientific Journal 2014; 10: 230-247.

2. Al-Jobair AM, Baidas LF, Al-Hamid AA, Al-Qahtani SG, Al-Najjar AT, Al-Kawari HM. Orthodontic treatment need among young Saudis attending public versus private dental practices in Riyadh. Clin Cosmet Investig Dent 2016; 8: 121-129.

3. Janošević P, Stošić $M$, Janošević $M$, Radojičić J, Filipović G, Čutović T. Index of orthodontic treatment need in children from the Niš region. Vojnosanit Pregl 2015; 72: 12-15.

4. Cruz López M, Gutiérrez Rojo M, Gutiérrez Rojo J, García A. Comparison between the ICON index and the esthetic component of the IOTN to determine the need for orthodontic treatment. Revista Mexicana de Ortodoncia 2017; 5: e10-e3.

5. Proffit WR, Fields HW, Sarver DM. Contemporary Orthodontics. St. Louis (MS); Elsevier Inc.; 2013.

6. Hassan AH. Orthodontic treatment needs in the western region of Saudi Arabia: a research report. Head Face Med 2006; 2: 2 .

7. Baeshen H. The Prevalence of Major Types of Occlusal Anomalies among Saudi Middle School Students. J Contemp Dent Pract 2017; 18: 142-146.

8. Singh N, Bagga D, Sharma R, Singh R. Evaluation of reliability of index of orthodontic treatment need for assessment of orthodontic treatment need. International Journal of Orthodontic Rehabilitation 2017; 8: 5-10.

9. Hassan AH, Hassan MH, Linjawi AI. Association of orthodontic treatment needs and oral health-related quality of life in Saudi children seeking orthodontic treatment. Patient Prefer Adherence 2014; 8: 1571-1579.
10. Shaj F, Jayarajan J, Vijayan A, Shukoor K. Assessment of Malocclusion among Patients Seeking Orthodontic Treatment at Dental College in Kerala, India. Inter J Pre Clin Den Res 2014; 1: 10-14.

11. Siddegowda R, Rani MS. A Cross-sectional Epidemiological Survey on Prevalence of Malocclusion in Government, Aided and Private School Children of Karnataka Universal. Journal of Public Health 2013; 1: 124-130.

12. Population by Gender, Governorate and Nationality (Saudi/ Non-Saudi) [cited 2010]. Available from: https://www.stats. gov.sa/sites/default/files/ar-makkah.pdf.

13. Carneiro EN, Pithon MM, Machado AW, Braga E. Perception of facial profile attractiveness of a brown subject displaying different degrees of lip projection or retrusion, in the city of Salvador/Bahia. Dental Press J Orthod 2018; 23: 62-67.

14. Rachel Henzell M, Margaret Knight A, Morgaine KC, Antoun JS, Farella M. A qualitative analysis of orthodontic-related posts on Twitter. Angle Orthod 2014;84: 203-207.

15. Omer YT, Bouserhal J, Hawas N, Abdel Moneim El Sayed A. Association between normative and self-perceived orthodontic treatment need in a Lebanese population. Int Orthod 2016; 14: 386-398.

16. Al-Zubair NM. Orthodontic treatment need of Yemeni children assessed with dental aesthetic index. J Orthod Sci 2014; 3: 41-45.

17. Hammad M, Awad M. Orthodontic treatment need in Egyptian schoolchildren. Pediatr Dent Journal 2013; 21: 39-43.

18. Cai Y, Du W, Lin F, Ye S, Ye Y. Agreement of young adults and orthodontists on dental aesthetics $\&$ influencing factors of self-perceived aesthetsics. BMC Oral Health 2018; 18: 113.

19. Zamzuri Szm, Abdul Raza I, Esa R. Normative and Perceived Need for Treatment of Malocclusion among Malaysian Adolescents. Sains Malaysiana 2014; 43: 1037-1043.

20. Nur Yilmaz RB, Oktay I, Ilhan D, Fişekçioğlu E, Özdemir F. Normative and subjective need for orthodontic treatment within different age groups in a population in Turkey. Niger J Clin Pract 2017; 20: 1632-1638.

21. Eslamipour F, Afshari Z, Najimi A. Prevalence of orthodontic treatment need in permanent dentition of Iranian population: A systematic review and meta-analysis of observational studies. Dent Res J (Isfahan) 2018; 15: 1-10.

22. Dalaie K, Behnaz M, Khodabakhshi Z, Hosseinpour S. Impact of malocclusion severity on oral health-related quality of life in an Iranian young adult population. Eur J Dent 2018; 12: 129-135.

23. Siddiqui TA, Shaikh A, Fida M. Agreement between orthodontist and patient perception using Index of Orthodontic Treatment Need. Saudi Dent J 2014; 26: 156-165.

24. Gudipaneni RK, Aldahmeshi RF, Patil SR, Alam MK. The prevalence of malocclusion and the need for orthodontic treatment among adolescents in the northern border region of Saudi Arabia: an epidemiological study. BMC Oral Health 2018; $18: 16$.

25. Jamilian A, Darnahal A, Damani E, Talaeipour M, Kamali Z. Prevalence of Orthodontic Treatment Need and Occlusal Traits in Schoolchildren. Int Sch Res Notices 2014; 2014: 349793.

26. Bugaighis I, Karanth D. The prevalence of malocclusion in urban Libyan schoolchildren. J Orthod Sci 2013; 2: 1-6. 